IZA DP No. 7751

Research and Teaching in Higher Education:

Complements or Substitutes?

Gil S. Epstein

Joseph Menis

November 2013 


\title{
Research and Teaching in Higher Education: Complements or Substitutes?
}

\author{
Gil S. Epstein \\ Bar-Ilan University, \\ CReAM and IZA \\ Joseph Menis \\ Bar-Ilan University \\ Discussion Paper No. 7751 \\ November 2013 \\ IZA \\ P.O. Box 7240 \\ 53072 Bonn \\ Germany \\ Phone: +49-228-3894-0 \\ Fax: +49-228-3894-180 \\ E-mail: iza@iza.org
}

Any opinions expressed here are those of the author(s) and not those of IZA. Research published in this series may include views on policy, but the institute itself takes no institutional policy positions. The IZA research network is committed to the IZA Guiding Principles of Research Integrity.

The Institute for the Study of Labor (IZA) in Bonn is a local and virtual international research center and a place of communication between science, politics and business. IZA is an independent nonprofit organization supported by Deutsche Post Foundation. The center is associated with the University of Bonn and offers a stimulating research environment through its international network, workshops and conferences, data service, project support, research visits and doctoral program. IZA engages in (i) original and internationally competitive research in all fields of labor economics, (ii) development of policy concepts, and (iii) dissemination of research results and concepts to the interested public.

IZA Discussion Papers often represent preliminary work and are circulated to encourage discussion. Citation of such a paper should account for its provisional character. A revised version may be available directly from the author. 
IZA Discussion Paper No. 7751

November 2013

\section{ABSTRACT \\ Research and Teaching in Higher Education: Complements or Substitutes?}

In this note we use unique data from Bar-llan University, over a period of four years (20052008), to estimate simultaneous equations with regard to the relationship between publications and teaching loads. The study shows that students studying for a bachelor's degree are a liability while PhD students are an asset in terms of publications. Those studying for a master's degree may be a liability or an asset depending on the department characteristics. Increasing the number of faculty members increases publications however it may not increase the publications per capita and is department specific.

JEL Classification: D2, L11

Keywords: productivity, publications, teaching loads, higher education

Corresponding author:

Gil S. Epstein

Department of Economics

Bar-Ilan University

Ramat Gan 52900

Israel

E-mail: gil.epstein@biu.ac.il 


\section{Introduction}

The purpose of this note is to consider the relationship between the different functions an academic researcher undertakes in the university. Scholars at the university play many roles such as: teaching undergraduate and graduate classes, supervision of graduate students, research, publications and submitting proposals for grants. All these tasks take time thus, is there a positive link between research and teaching?

The relationship between teaching and publications has been analyzed in different respects. For example Fox (1992) considers a similar type of question. In her paper Fox (1992) assesses two theoretical views about which there has been considerable, unresolved speculation: the mutuality versus the competition of research and teaching in academia. Going beyond previous restrictions in aims and methods of analysis, it evaluates the influence of research and teaching interests, time commitments, and orientation of the various faculties and their perceived environments on the publication productivity of social scientists in BA-, MA-, and Ph.D.-degree granting departments in four fields. Contrary to the mutuality perspective, the findings point to a strain between research and teaching: Those whose publication productivity is high have strong investments in research, but not in teaching. These findings suggest that research and teaching do not represent aspects of a single dimension of academic investments, but are different, conflicting dimensions. The relationships are stronger for the faculty in BA- than in the Ph.D.granting departments. Fox (2005) considers the relationship between marriage, parental status, and publication productivity for women in academic science, in comparison to men. Findings indicate that gender, family characteristics, and productivity are complex considerations that go beyond being married or not married, and the presence or absence of children. In a later paper Hattie and Marsh (1996) present a review of various models of the relationship between research and teaching in universities, where the evidence necessary to assess each model is outlined. A meta-analysis of 58 studies demonstrates that the relationship is zero. Suggestions for future directions are provided, and it is argued that a major goal could be to adopt strategies which enhance the relationship between research and teaching.

It has become increasingly clear over the past decade that the question of a positive link between research and teaching has no simple or general answer. At the same time, there may well be a positive link under particular conditions. Elton 
(2001) argues that a positive link can be due primarily to the processes, rather than the outcomes, inherent in research and teaching, and that, in particular, student-centered teaching and learning processes are intrinsically favorable towards a positive link, while more traditional teaching methods may, at best, lead to a positive link for the most able students, who, in the perception of traditional academics. are, of course, the future university teachers. This finding, in turn, leads to a rational explanation of the persistent myth of a general positive link. Finally, it is argued that pedagogic research and its outcomes could play an important role in strengthening the link.

In this study we present results based on data collected from 37 departments at Bar-Ilan University over four years (2005-208). We start by describing the data and the different relationships between the variables. We then consider theoretical aspects of the relationship and finally estimate simultaneous equations which consider the different relationships between the variables.

Our results show that, on average, increasing the number of students studying for a bachelor's degree decreases publications and grants, while increasing the number of students studying for a Master's Degree has an ambiguous effect on the number of publications and grants awarded (depending on the department). Increasing the number of $\mathrm{PhD}$ students increases the number of publications and grants attained. We also carry out a sensitivity analysis, considering the effect an increase in faculty in a department would have on the number of publications. We show that an increase in faculty will increase publications; however, its effect on the number of publications per capita is ambiguous and depends on the characteristics of the department.

\section{Descriptive Data}

Our analysis deals with students, the number of grants awarded, publications and the interconnection between them. These variables are directly related and also related to the size of the faculty in each department. We thus normalize the number of publications, grants and students by the size of the faculty: "per capita" (notice that some of the faculty work part time, and thus the number of faculty members may not be an integer). Table 1 presents the descriptive data for each department. We start by considering the relationship between the number of students per capita and the number of publications and grants per capita - a two dimension description.

From figure 1 we conclude that there is a negative relationship between the number of publications per capita (faculty members) and the number of students on a 
BA level per capita. From figure 2 and 3 we conclude that the relationship between the number of students learning for an $\mathrm{MA}$ and $\mathrm{PhD}$ degree per capita and the number of publications per capita, is unclear.

Turning to grants, we obtain the following results: Figure 4 and 6 show that it is hard identify a direct relationship between the number of BA students and $\mathrm{PhD}$ students per capita and the number of grants awarded per capita while in figure 5 the relationship between grants attained and the number of MA students per capita seems to be negative.

\section{Correlations}

From the figures presented above, it is somewhat hard to determine the relationship between the different variables. In order to get a better picture we calculate a simple correlation between the variables presented above:

\begin{tabular}{|c|c|c|c|}
\hline & $\begin{array}{c}\text { BA students per } \\
\text { Faculty }\end{array}$ & $\begin{array}{c}\text { MA students per } \\
\text { Faculty }\end{array}$ & $\begin{array}{c}\text { PhD students } \\
\text { per Faculty }\end{array}$ \\
\hline Publications per & -0.217 & 0.212 & 0.502 \\
Faculty & $(0.031)$ & $(0.036)$ & $(0.000)$ \\
\hline Grants awarded per & -0.304 & -0.241 & 0.344 \\
Faculty & $(0.04)$ & $(0.020)$ & $(0.001)$ \\
\hline
\end{tabular}

The number in the brackets represents the $P$ values.

All correlations are significant at a $5 \%$ level.

These results show: On average, increasing the number of students studying for a Bachelors' degree (BA) decreases publications and grants, while increasing the number of students studying for a Master's Degree (MA) may increase or decrease publications and grants (depending on the department). Increasing the number of PhD students increases the number of publications and grants.

This finding shows students learning for a bachelors' degree (BA) are a liability in terms of publications and grants while $\mathrm{PhD}$ students are an asset in terms of publications and grants. On the other hand, students learning for their MA studies may be either a liability or an asset in terms of publications and grants. This may well depend on the type of degree (department and faculty). 


\section{The Model}

In this section we describe the relationship between the variables in a generalized framework. We divide the variables into three groups:

a. research activities,

b. students;

c. number of researchers at each level in the department,

Let us start by defining the variables for each department at the university:

a. Research activates - dependant variable $(z)^{1}$,

1. Number of publications $-z_{1}$ and 2. Number of research grants won $-z_{2}$

Independent variables

b. Number of students at each level $-\mathrm{x}$

1. Bachelor's degree (BA) - $x_{1}$;

2. Master's Degree (MA) - $x_{2}$;

3. Ph.D degree (MA) - $x_{3}$;

c. Number of appointments at each department $-\mathrm{q}$

1. Assistant lecture $-q_{1} ;$ 2. Lecture $-q_{2} ;$ 3. Senior Lecturer $-q_{3}$;

4. Associate Professor $-q_{4} ;$ 5. Professor $-q_{5} ;$ 6. Teachers $-q_{6}$.

We consider the relationship between the teaching activities and the research activities in department $k$ when the number of students and faculty members are fixed. It is important to note that within the research variables, publications and research grants, one cannot easily look at each aspect separately as one can depend on the other. As the number of publications increase the probability of winning a grant may increase. As the number of grants won increases the researcher has more funds to invest in research and may increase the probability and number of publications. Thus, publications and grants are determined simultaneously and have to be examined in such a manner.

\footnotetext{
${ }^{1}$ We assume that all publications are identical, even though it is clear that the quality of the journal, number of co-authors and length of the paper are important variables, unfortunately we did not have this data and assume that this is similar in all department and thus cancel out each other.
} 
This relationship is determined simultaneously. In the empirical estimation other independent variables are needed in order to obtain an identification.

(1) $z_{1 k}=\alpha_{1}+\sum_{j=1}^{4} \sum_{i=1}^{3} \beta_{i j k} x_{i j k}+\sum_{j=1} \sum_{i=1} \delta_{i j k} q_{i j k}+\sum_{j=1} \sum_{i=1} \lambda_{i j k} y_{i j k}+\eta_{1} z_{2 k}+\tau_{k} S_{k}+u_{k}$
(2) $z_{2 k}=\alpha_{2}+\sum_{j=1}^{4} \sum_{i=1}^{3} \gamma_{i j k} x_{i j k}+\sum_{j=1} \sum_{i=1} \phi_{i j k} q_{i j k}+\sum_{j=1} \sum_{i=1} \mu_{i j k} y_{i j k}+\eta_{2} z_{1 k}+\omega_{k} W_{k}+v_{k}$

Where

1. $u$ and $v$ are the random variables;

2. the coefficient vector $(\beta, \delta, \lambda, \eta, \tau, \omega)$ represent the substitution of research and teaching with regard to the different levels of teaching (between the different levels of the research).

3. S and W are exogenous variables, which are given and cannot be changed. An example of these variables would be dependant lag variables such as: lags in the number of students, lags in number of publications, lags in number of grants, size of the classrooms in the past, the number of administrative workers in each department etc.

This model examines the substitution between the variable "teaching", the number of publications and research grants. The equations must be estimated simultaneously since each of the variables feeds into the other: the number of publications depends on the number of students, number of students and research grants per lecturer. On the other hand the number of grants depends on the number of students per lecturer and the number of students per publication. Thus the number of publications depends on the research grants and research grants depend on the number of articles published. Of course, dependence can be over time, i.e. the number of students today can affect the number of publications and grants tomorrow and they may affect the number of publications in the future. Hence in the simplest system we could think of the different elements of the model feeding back into each other. Let us consider each of the equations:

The first equation shows us that a number of publications $\left(Z_{l}\right)$ in a particular class $(k)$ is determined by the number of students each year and the degree $(x-\mathrm{a}$ vector of the number of students for each year at the university, first, second and third 
year ${ }^{2}$ for the bachelor's degree; first, second, third and fourth for the Master's degrees for the PhD studies etc.). Also, the number of publication $\left(Z_{l}\right)$ depends on the number of faculty members at each level/rank $(q)$ and the teaching load (number of students per faculty member in each rank, type of course and degree etc. - marked by $y$ ). The number of publications depends on the number of research grants won $\left(z_{2}\right)$ and finally on other exogenous variables (such as number of publications last year, the number of articles in the past, the number of students in the past, the size of classrooms, administration, etc..)

Second equation, is similar to the first equation and looks at the relationship between the number of research grants $\left(z_{2}\right)$ and the number of students each year, the teaching load, number of faculty members at each level and the number of publications.

The system of equations is simultaneous. We estimate the regression coefficients $(\beta, \delta, \lambda, \eta, \tau, \omega)$ which show us the value of various parameters in terms of other parameters. For example, if we know the value of the vector $\beta$-we would be in a position to know how an increasing the number of students, in the first year of the bachelor's studies, would affect the number of publications of that department. It is clear that increasing the number of first year students' teaching load will affect and influence the amount of publications. Increasing the number of students has an effect, via equation (2), on the number of grants and this will have an effect on the number of publications, as presented in equation (1).

The number of publications is affected by all sorts of other random effects. These effects are accounted for by the random variables $u$ and $v$.

The model is estimated by using the TSLS method for simultaneous equations. The outcome of the model will allow us to see for example, how increasing the number of graduate students per year will affect the number of articles and publications in the same department and enable us, by various simulations, to assess the value of the students and the grants, in terms of the number of the research publications. It should be noted, that in certain departments, increasing the number of $\mathrm{PhD}$ students, increases research productivity, while in other departments it may decrease publications. Since this analysis is performed in various departments within

\footnotetext{
${ }^{2}$ In Israel, the course for a bachelor's degree is 3 years.
} 
the university, we will be able to determine in which department the students' effect on research is low.

\section{Estimation}

Based on the four year sample, two simultaneous equations were estimated to analyze the relationship between the research productivity and the teaching load.

The two equations which were estimated are: The number of publications and the number of grants per faculty member as a function of:
A. Number of BA students per faculty member;
B. Number of MA students per faculty member;
C. Number of PhD students per faculty member;
D. Department.

Since there is a connection between the quantity of publications and research grants, the equations were estimated simultaneously. Equations were estimated with the possibility of examining the structural change of the functions for the different departments, namely the equations were estimated with dummy variables for each department (department fixed effects and changes in the slopes). Since we are using panel data, the regressions also include yearly fixed effects for all four years.

The main regression, which we are interested in estimating, is the publication's regression. We needed an instrumental variable to indentify this regression. The instrument used is the number of administrative workers in each department. We were not able to identify the grant's regression. ${ }^{3}$

67 variables were in the regression. $\mathrm{R}$ square equals $93 \%$ and is significant at any significance level. In table 2 we present the coefficients by departments. All coefficients are significant at a $5 \%$ or at a lower significant level.

Carrying out a Wald test to check whether the departments have a significant effect on the outcome, the hypothesis that the departments do not have an effect was rejected at any significant level.

3 Note, that when running the regression separately for each department, we obtained, in most cases, the same coefficients with the same signs as in the general regression (as a result of a small number of observations these regression did not include the number of $\mathrm{PhD}$ students per faculty members). 
The results show is that in most of the departments increasing the number of BA students per capita decreases the number of publications per capita, while increasing the number of $\mathrm{PhD}$ or MA students per capita may increase or decrease the number, depending on the department. There are departments where increasing the number of students seems to increase the number of publications per capita: Department of Integrated Life Sciences, History of the Middle East, Israel Studies, Information Studies, Hebrew Language, Mathematics, History of Israel and French Culture. These departments are relatively small departments with regard to the number of students and research (except for Mathematics). ${ }^{4}$ The number of students learning for higher degrees may increase or decrease the productivity of the researchers.

Using the coefficients obtained, we may now calculate how a change in the number of faculty members by one unit will affect the number of publications (given that the number of students does not change).

We carry out the following exercise (presented in table 3): Keeping the number of students fixed, we consider the effect of increasing (in each department) the number of faculty members by one and then consider how it will affect the number of publications. In the second column we present the actual number of faculty members, while in the third column we present the change in the number of publications per capita as a result of an increase of one in the number of faculty members. In the fourth column we present the current number of publications per faculty member.

As we can see from the results, either there is a positive relationship between the two or it is hard to determine the total affect (denoted by "-_). In general we can see that there are departments, such as the department for English studies, where the current ratio of publications to faculty member equals to 1.55 while increasing the faculty members by one increases the publications by less than 0.5 . This means that increasing the number of faculty members decreases the publications per member instead of increasing it as we would have expected.

On the other hand, in a department such as the Chemistry dep., increasing the number of faculty members by one unit increases the number of publications by 4.75 . Note that the number of publications per faculty equals 1.38. This means that increasing the faculty by one member decreases the teaching load sufficiently to

\footnotetext{
${ }^{4}$ The Departments: School of Business Administration and Translation studies do not have a bachelor's program.
} 
produce a higher number of publications and increase the publications per faculty member.

In most departments increasing the faculty members by one unit increases the number of publications per capita. If we compare the increase in the number of publications with the average number per capita we can verify if the number will increase with the boost in the number of faculty members. If the increase in the number of publications in column 3 is greater than the publications per faculty (before the increase) presented in column 4 , then these will grow as a result of escalating the faculty members. However, if it is smaller, then increasing the number of faculty members by one unit will decrease the publications per faculty.

There are two main reasons why increasing the number of faculty members may swell the publications per faculty member:

1. Increasing the number of faculty members with a given number of students decreases the burden on each of the faculty members and enables them to invest more time for research. Note that we are holding constant the number of students for all degrees. Thus, the effect presented is an average one, since in some degree, building up the number of faculty members, without increasing the number of students, may decrease publications. This would happen when the students and publications are complementary. For example if the researchers need students to run their labs, adding on to the faculty size without augmenting the number of students may well decrease the number of publications. On the other hand, this addition to the faculty may decrease the teaching load and give the researchers more time (resources) to spend on research.

2. Increasing the number of faculty members may build up the publications per capita as a result of competition between faculty members. On the other hand, if researchers complement each other, then having more researchers working together will help increase publications rather than decrease them.

\section{Concluding remarks}

In this note we considered the relationship between the responsibilities of teaching, reflected by the number of students, on the publication productivity of the researchers in the university at the department level. We used a unique data from an Israeli university and analyzed this relationship. We began by presenting general descriptive data and then presented a more formal model which we carried through to the data. 
Both the descriptive analysis and the deeper simultaneous equation analysis provide, on average, the same type of results: Increasing the number of students in the bachelor's degree decreases the number of publications while increasing the number of students in the advanced degrees may increase or decrease the number of publication per capita. This relationship depends on the department characteristics.

Based on the simultaneous equations we compute whether increasing the faculty members, in a certain department, will increase the publications and publications per capita. Increasing the number of faculty members increases publications but may or may not increase the publications per capita. This is very department specific.

\section{References}

Elton L 2001, "Research and Teaching: conditions for a positive link", Teaching in Higher Education 6(1) 43-56

Fox. M.F. 1992, "Research, Teaching and Publication Productivity: Mutuality verses Competition in Academia" Sociology of Education 65, 293-305

Fox M.F. 2005 “Gender, Family Characteristics, and Publication Productivity among Scientists” Social Studies of Science 35(1), 131-150.

Hattie J. and Marsh H.W. 1996, "The Relationship between Research and Teaching: A Meta-Analysis” Review of Education Research 66(4) 506-542 


\section{Appendix}

Definitions:

1. BA per faculty is the number of students in that particular department learning for a Bachelor's Degree, divided by the size of that faculty;

2. MA per faculty is the number of students in that particular department learning for a Master's Degree, divided by the size of the faculty;

3. PhD per faculty is the number of students in that department learning for a $\mathrm{PhD}$ Degree, divided by the size of the faculty;

4. Publications per faculty are the number of publications in that department, divided by the size of the faculty;

5. Grants per faculty are the number of grants won in the department, divided by the size of the faculty. 
Table 1 - Descriptive Data

\begin{tabular}{|c|}
\hline Department \\
\hline English \\
\hline School of Engineering \\
\hline $\begin{array}{l}\text { School of Business } \\
\text { Administration }\end{array}$ \\
\hline School of Social Work \\
\hline School of Education \\
\hline $\begin{array}{l}\text { Geography and } \\
\text { Environment }\end{array}$ \\
\hline $\begin{array}{l}\text { Department of Integrated } \\
\text { Social Sciences }\end{array}$ \\
\hline $\begin{array}{c}\text { Department of Integrated } \\
\text { Life Sciences }\end{array}$ \\
\hline History \\
\hline $\begin{array}{c}\text { History of the Middle } \\
\text { East }\end{array}$ \\
\hline Faculty of Life Sciences \\
\hline Faculty of Law \\
\hline Chemistry \\
\hline Economics \\
\hline Israel Studies \\
\hline Information Studies \\
\hline Interdisciplinary studies \\
\hline Classic Studies \\
\hline Hebrew Language \\
\hline Political Science \\
\hline Computer Science \\
\hline Music \\
\hline Mathematics \\
\hline $\begin{array}{l}\text { Sociology and } \\
\text { Ornithology }\end{array}$ \\
\hline Comparative Literature \\
\hline Israeli Literature \\
\hline Arabic \\
\hline Philosophy \\
\hline Physics \\
\hline Psychology \\
\hline Criminology \\
\hline History of Israel \\
\hline Talmud \\
\hline Bible \\
\hline French Culture \\
\hline Translation studies \\
\hline
\end{tabular}

\section{BA per}

Faculty

8.254217901

41.04129264

0

17.06278027

12.17132697

10.52894429

112.9090584

37.93788795

8.952748274

20.59180036

17.54747675

23.83211679

13.16063643

37.73388588

10.46593895

14.82583151

9.84544406

4.298507388

6.183920873

27.92915331

27.37962951

6.648910387

14.50449194

25.04361755

5.160826588

5.472858349

13.27622841

4.158989569

5.064648839

8.950812886

29.50510783

6.246832634

2.404679917

3.505598587

5.776315789

0
MA per

Faculty

4.868458679

0

50.61941094

14.48166711

15.56812672

5.437003405

8.458646617

0

3.317261331

5.401069519

3.876992032

37.98813869

2.55648038

7.309761044

5.874772589

34.50097847

18.69665513

0.447761194

4.185786234

20.34575052

7.785947712

4.430992736

3.140981341

12.06159872

3.4393531

3.99173028

8.087649402

5.111441308

1.237878343

5.921001778

12.1906924

3.78112713

7.556779078

4.341085271

1.096491228

21.18589744
Ph.D per

Faculty

2.545038605

0.448833034

1.739273115

1.727776312

2.618393406

1.566401816

0.035803795

2.608695652

2.237222758

3.814616756

3.43625498

1.61040146

3.6775947

0.837668636

3.259551243

4.657534247

16.48212226

0.820895522

2.79798545

1.755078759

2.794117647

3.147699758

1.596406358

2.118568631

2.458221024

4.007633588

3.027888446

3.580980684

1.660299736

4.614671098

3.450624291

2.214941022

2.339986235

1.860465116

1.096491228

1.41025641
Publications per faculty

1.558335716

0.128067026

2.500123062

1.731337378

1.479747858

0.836095346

0.957214465

3.872049689

1.996142719

2.403565062

0.796663347

1.903284672

1.386274843

1.47711842

3.073832626

1.518982387

4.577623991

2.164179104

2.137660884

1.472774341

1.402614379

0.855447942

0.990601244

1.337190671

1.660377358

2.65187659

0.928685259

2.50282318

2.116147517

0.992734019

0.895573212

2.753342071

2.188575361

3.999483204

1.560526316

1.758974359
Grant per

Faculty

0

0.029922202

0

0

0.019395507

0.022701476

0.008950949

0.186335404

0

0.035650624

0.254780876

0.022810219

0.106166129

0.008817565

0.015160703

0.058708415

0.092272203

0.022383884

0.114379085

0.04842615

0.05300622

0.017803098

0.031806616

0.079681275

0.029717682

0.091830738

0.069567906

0.04587156

0.02752925

0.025839793

0.096153846 
Table 2 - Regression Estimates

\begin{tabular}{|c|c|c|c|c|}
\hline & \multicolumn{4}{|c|}{ Simultaneous Equation } \\
\hline Department & $\mathbf{B A}$ & MA & PHD & Intercept \\
\hline English & -0.019 & 0.472 & -0.703 & 15.038 \\
\hline School of Engineering & -0.019 & - & 0.96 & 0.41 \\
\hline $\begin{array}{l}\text { School of Business } \\
\text { Administration }\end{array}$ & - & -0.08 & 1.897 & 3.03 \\
\hline School of Social Work & -0.019 & 0 & -0.703 & 3.03 \\
\hline School of Education & -0.019 & 0.023 & -0.703 & 3.03 \\
\hline $\begin{array}{l}\text { Geography and } \\
\text { Environment }\end{array}$ & -0.019 & 1.139 & -0.703 & 3.03 \\
\hline $\begin{array}{c}\text { Department of Integrated } \\
\text { Social Sciences } \\
\end{array}$ & -0.019 & 0.016 & -0.703 & 3.03 \\
\hline $\begin{array}{c}\text { Department of Integrated } \\
\text { Life Sciences }\end{array}$ & 0.474 & - & -0.135 & -13.147 \\
\hline History & -5.604 & 10.792 & 0.877 & 14.1 \\
\hline $\begin{array}{c}\text { History of the Middle } \\
\text { East }\end{array}$ & 0.41 & -0.328 & -0.703 & -1.64 \\
\hline Faculty of Life Sciences & -0.019 & 0.472 & -0.703 & 3.03 \\
\hline Faculty of Law & -0.019 & 0.01 & -0.703 & 3.03 \\
\hline Chemistry & -0.019 & 0.472 & -0.703 & 3.03 \\
\hline Economics & -0.019 & -0.065 & -0.703 & 3.03 \\
\hline Israel Studies & 1.446 & 0.472 & -0.703 & -12.7 \\
\hline Information Studies & 0.784 & 0.472 & -3.759 & -8.068 \\
\hline Interdisciplinary studies & -0.019 & 0.482 & -0.703 & 3.03 \\
\hline Classic Studies & -0.019 & -0.966 & & 3.03 \\
\hline Hebrew Language & 0.683 & -0.799 & -0.703 & 3.03 \\
\hline Political Science & -0.019 & 0.472 & -0.703 & -6.61 \\
\hline Computer Science & -0.019 & 0.143 & -0.703 & 3.03 \\
\hline Music & -0.019 & 0.472 & 2.067 & -7.669 \\
\hline Mathematics & 0.282 & -1.6 & -0.703 & 3.03 \\
\hline $\begin{array}{l}\text { Sociology and } \\
\text { Ornithology }\end{array}$ & -0.241 & 0.472 & -0.703 & 3.03 \\
\hline Comparative Literature & -0.019 & -1.931 & -0.703 & 9.873 \\
\hline Israeli Literature & -0.019 & 0.472 & -0.575 & 3.03 \\
\hline Arabic & -0.019 & 0.472 & -0.703 & 0.43 \\
\hline Philosophy & -3.02 & 0.037 & -7.03 & 15.038 \\
\hline Physics & -0.019 & 0.472 & -0.703 & 3.03 \\
\hline Psychology & -0.019 & -0.618 & 0.411 & 3.03 \\
\hline Criminology & -0.364 & 2.976 & -8.1 & 3.03 \\
\hline History of Israel & 1.218 & 0.472 & 5.757 & -19.438 \\
\hline Talmud & -1.99 & 0.472 & 0.084 & 3.03 \\
\hline Bible & -0.019 & 0.472 & -0.703 & 3.03 \\
\hline French Culture & 4.97 & 3.935 & -16.115 & -14.058 \\
\hline Translation studies & - & 0.472 & 2.118 & -11.046 \\
\hline \multicolumn{2}{|l|}{ R square: 0.967} & F Value & \multicolumn{2}{|c|}{ P value $:<0.000$} \\
\hline \multicolumn{2}{|c|}{ Number of observations: 144} & \multicolumn{3}{|c|}{ Degrees of Freedom : 76} \\
\hline
\end{tabular}


Table 3 - changes in faculty and its affect on publications

\begin{tabular}{|c|c|c|c|}
\hline Department & \# Faculty & Change in faculty & Publications per faculty \\
\hline English & 10.33 & 0.443003 & 1.558335716 \\
\hline School of Engineering & 7.00 & 1.04 & 0.128067026 \\
\hline $\begin{array}{l}\text { School of Business } \\
\text { Administration }\end{array}$ & 11.83 & 2.739205 & 2.500123062 \\
\hline School of Social Work & 21.23 & 2.538666 & 1.731337378 \\
\hline School of Education & 36.90 & 2.58857 & 1.479747858 \\
\hline $\begin{array}{c}\text { Geography and } \\
\text { Environment }\end{array}$ & 7.70 & - & 0.836095346 \\
\hline $\begin{array}{c}\text { Department of } \\
\text { Integrated Social } \\
\text { Sciences }\end{array}$ & 15.50 & 2.02125 & 0.957214465 \\
\hline $\begin{array}{c}\text { Department of } \\
\text { Integrated Life } \\
\text { Sciences }\end{array}$ & 1.70 & - & 3.872049689 \\
\hline History & 4.28 & - & 1.996142719 \\
\hline $\begin{array}{c}\text { History of the Middle } \\
\text { East }\end{array}$ & 5.45 & - & 2.403565062 \\
\hline Faculty of Life Sciences & 39.70 & 1.75417 & 0.796663347 \\
\hline Faculty of Law & 23.20 & 2.19978 & 1.903284672 \\
\hline Chemistry & 20.98 & 4.754274 & 1.386274843 \\
\hline Economics & 27.43 & 2.032745 & 1.47711842 \\
\hline Israel Studies & 12.95 & - & 3.073832626 \\
\hline Information Studies & 8.20 & - & 1.518982387 \\
\hline $\begin{array}{c}\text { Interdisciplinary } \\
\text { studies }\end{array}$ & 10.98 & 7.305404 & 4.577623991 \\
\hline Classic Studies & 2.85 & 6.10071 & 2.164179104 \\
\hline Hebrew Language & 9.45 & 1.60512 & 2.137660884 \\
\hline Political Science & 27.13 & - & 1.472774341 \\
\hline Computer Science & 12.30 & 4.44885 & 1.402614379 \\
\hline Music & 11.20 & - & 0.855447942 \\
\hline Mathematics & 28.80 & 2.79524 & 0.990601244 \\
\hline $\begin{array}{c}\text { Sociology and } \\
\text { Ornithology }\end{array}$ & 13.23 & 2.420523 & 1.337190671 \\
\hline $\begin{array}{c}\text { Comparative } \\
\text { Literature }\end{array}$ & 6.95 & - & 1.660377358 \\
\hline Israeli Literature & 14.95 & 2.63813 & 2.65187659 \\
\hline Arabic & 6.95 & - & 0.928685259 \\
\hline Philosophy & 12.45 & - & 2.50282318 \\
\hline Physics & 25.78 & 3.49479 & 2.116147517 \\
\hline Psychology & 25.63 & 4.497807 & 0.992734019 \\
\hline Criminology & 12.50 & 3.1293 & 0.895573212 \\
\hline History of Israel & 12.95 & - & 2.753342071 \\
\hline Talmud & 17.10 & 1.68873 & 2.188575361 \\
\hline Bible & 15.95 & 0.510195 & 3.999483204 \\
\hline French Culture & 4.95 & - & 1.560526316 \\
\hline Translation studies & 5.45 & - & 1.758974359 \\
\hline
\end{tabular}


The Relationship between Students and Publication

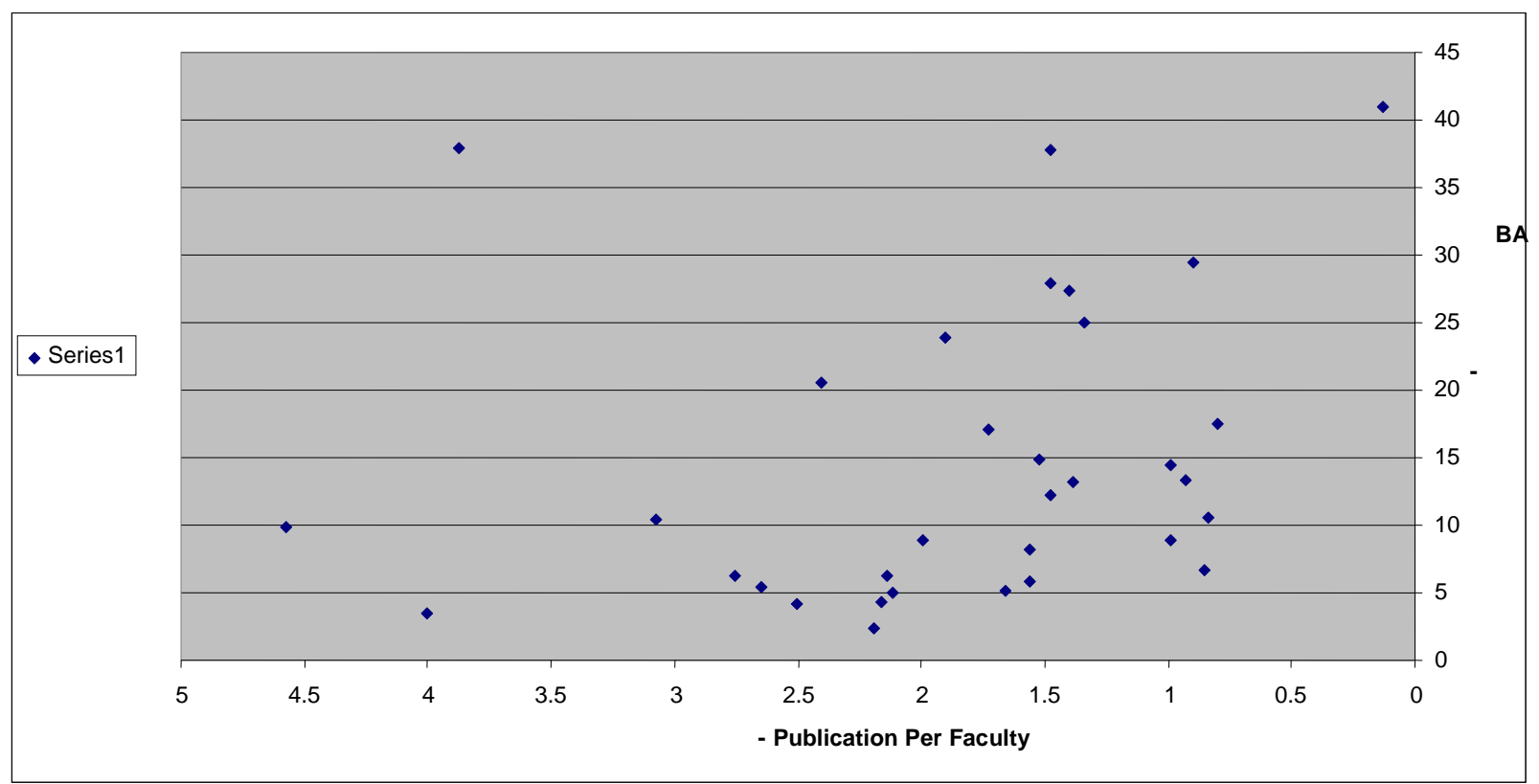

Figure 1: Publications per capita and the number of BA students per capita

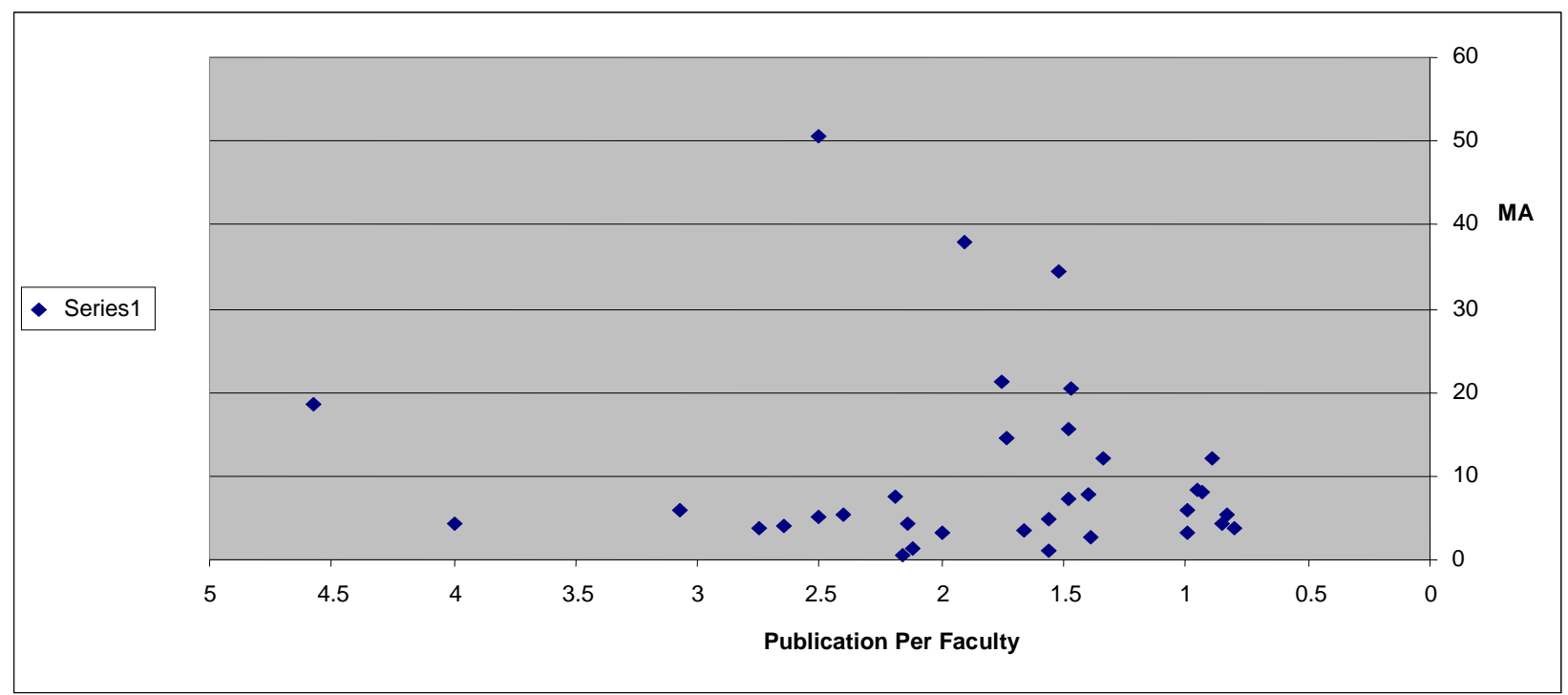

Figure 2: Publications per capita and the number of MA students per capita 


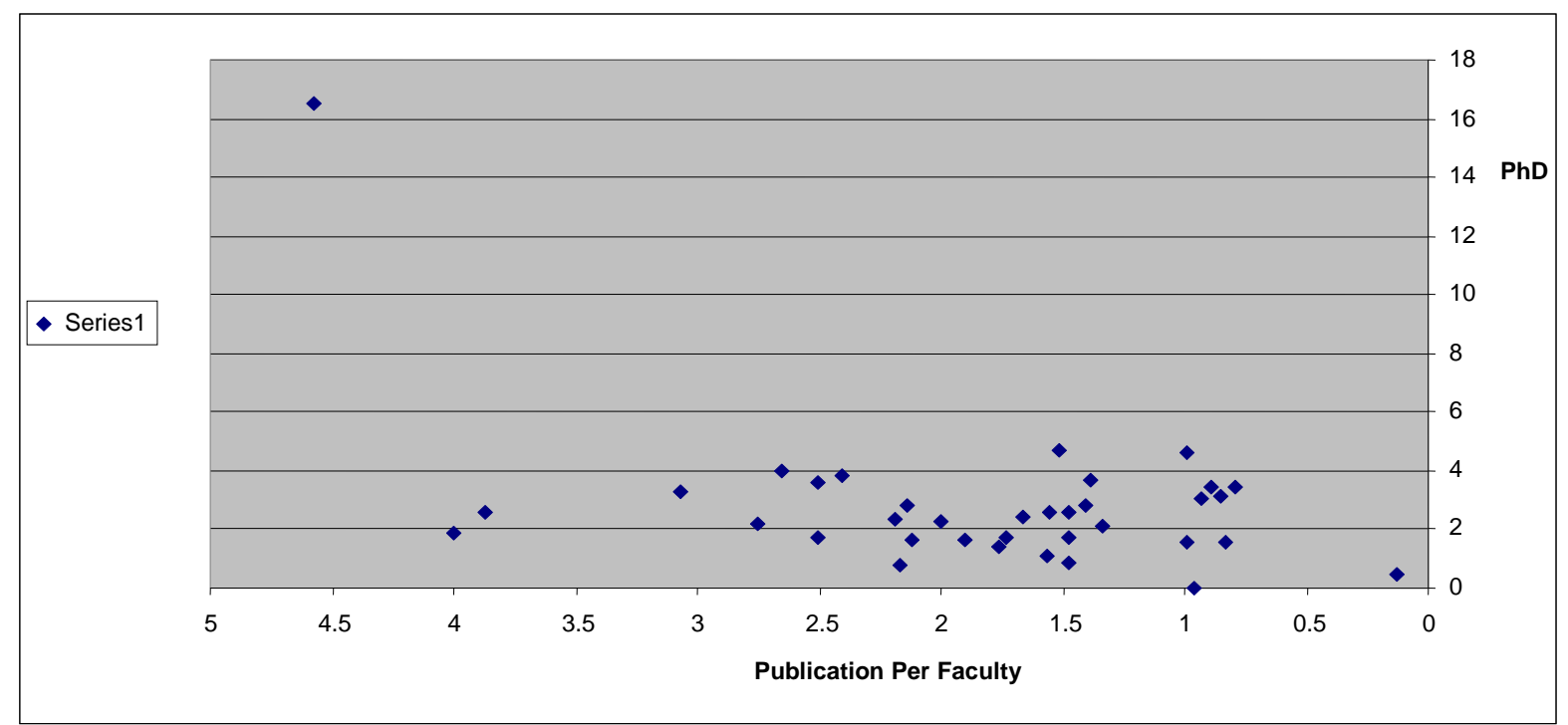

Figure 3: Publications per capita and the number of $\mathrm{PhD}$ students per capita 
The Relationship between Students and Grants

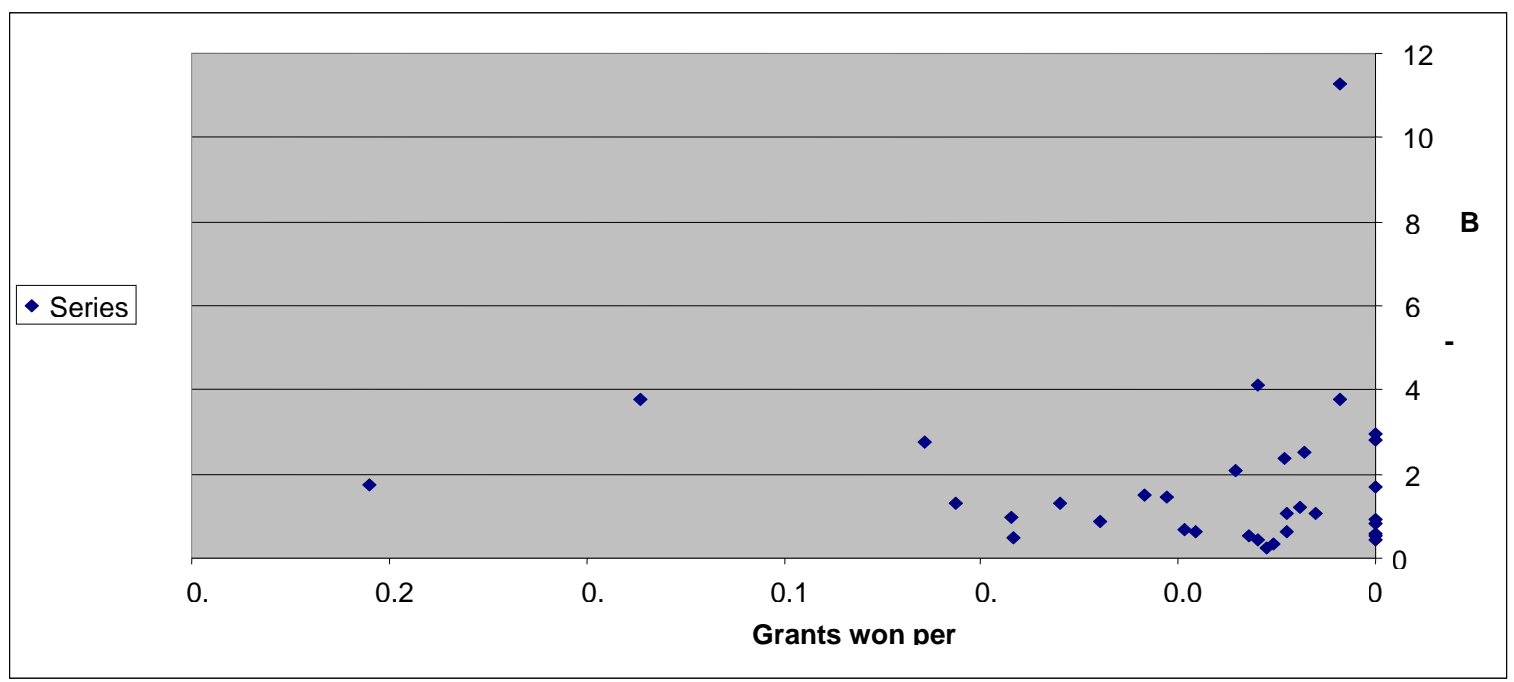

Figure 4: Grants per capita and the number of BA students per capita

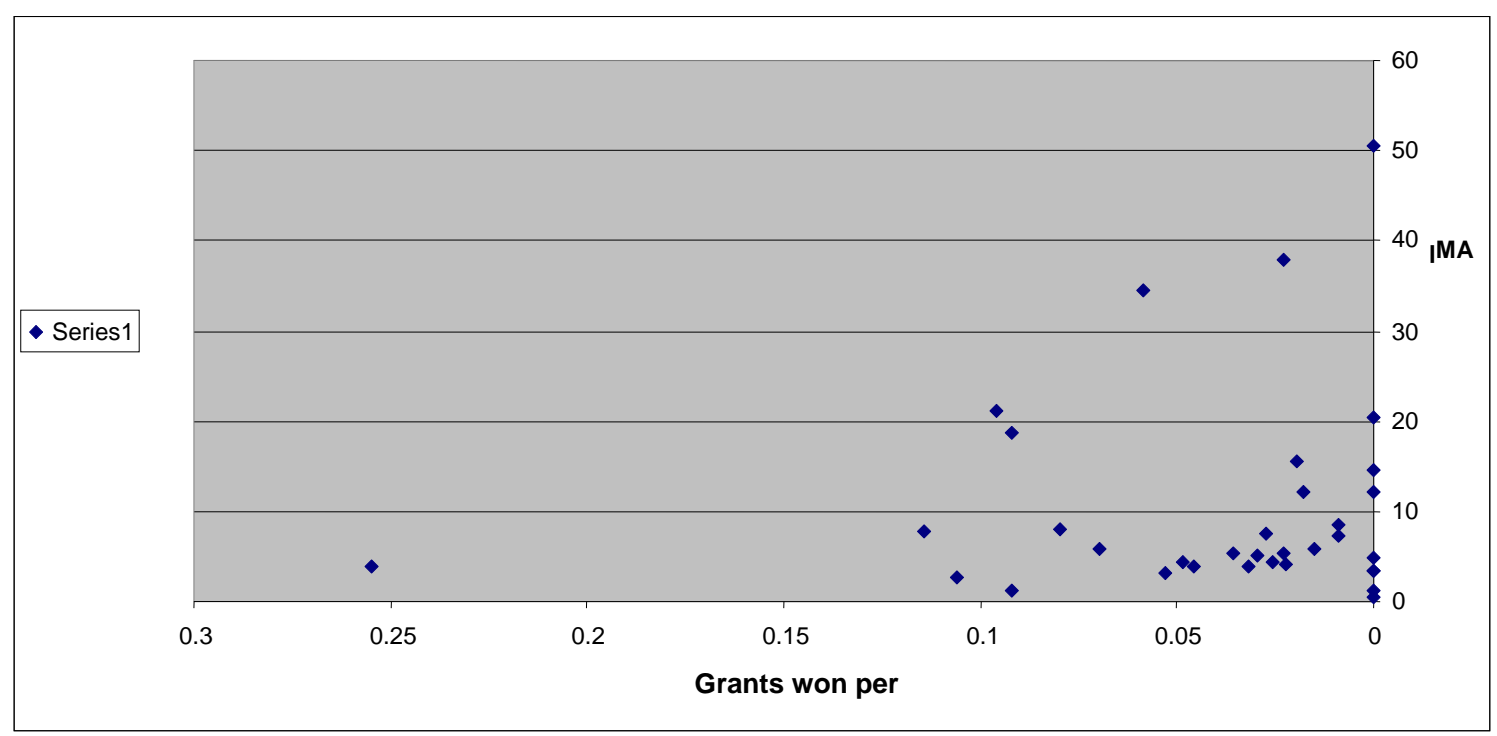

Figure 5: Grants per capita and the number of MA students per capita 


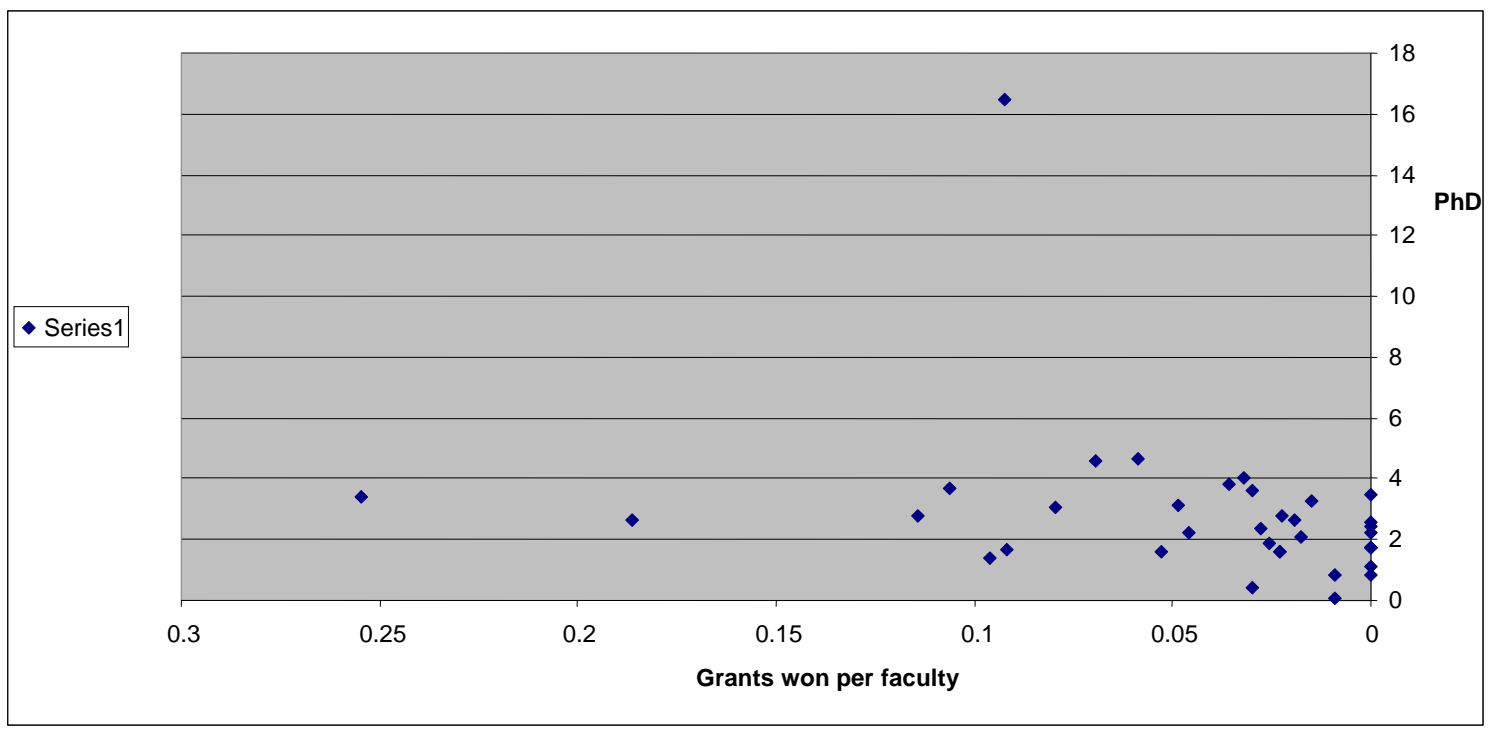

Figure 6: Grants per capita and the number of $\mathrm{PhD}$ students per capita 